\title{
PRACTICAL PHENOMENOLOGY AND THE OSH INSPECTOR
}

\author{
Mike Lloyd \\ School of Social and Cultural Studies \\ Victoria University of Wellington
}

\begin{abstract}
This paper stems from the chance acquisition of data on Occupational Safety and Health work: a National Radio Spectrum documentary where a presenter 'spent the day' with an OSH inspector. This collection of talk about what the OSH inspector's work involves has been transcribed and is analysed here through the concept of 'practical phenomenology' (Atkinson 1995). That is, we see an expert concerned, as a matter of everyday work, with the nature of what he sees about him and how this might be described. What is identifiable as a hazard or risk in the workplace, and how can that be described to a range of other people, including bosses and workers in the workplace, professionals in other institutions, and of course the 'overhearing' radio audience? Hence, the practical adequacy of the OSH inspector's work turns on the use of everyday resources, fundamentally the use of language. But it is not language in itself that is key, rather, we must attend to what people do with language - how the OSH inspector's descriptions, pleas, warnings, and so on, are responded to by those he talks with. This is an important part of the practical accomplishment of OSH's work in trying to improve health and safety in the workplace.
\end{abstract}

\section{Introduction}

As the title indicates, this article has two components: 'practical phenomenology', and 'the OSH inspector'. General details of OSH (Occupational Safety and Health) should be familiar enough through recent publications (e.g., Duncan 2003; Lamm 2000; Lloyd 2002; Slappendel 1995), and LEW conferences themselves as these have been an important forum for OSH research. The former practical phenomenology - will be strange to many, hence the first step will be to explain the concept. Empirical analysis is then presented, and, if this is successful, we realise a dual product: we learn about the social organisation of $\mathrm{OSH}$ inspection; and we can reflect upon the merits of practical phenomenology as a conceptual tool. Where else can practical phenomenology be found, and what are the consequences of thinking via this concept?

Phenomenology has a lineage generally traced back to Husserl and developments within European philosophy (see Ferguson 2001). This lineage need not concern us here, as the more specific term 'practical phenomenology' is taken from recent work (1995) by the sociologist Paul Atkinson. Atkinson's 'micro-sociology of medical knowledge' (1995:1) is based on ethnographic fieldwork among haematologists - the medical specialists who deal with disorders of the blood system - in American and British teaching hospitals. He is concerned with the practical organisation of this specialty: how haematologists define and adjudicate the presence of disease, and how they discuss, negotiate and transmit their expert knowledge amongst other medical colleagues (1995:2). Atkinson's interest is not the content of haematologist's knowledge, but the forms of talk and interaction through and in which this expert knowledge is realised: how, practically, in their everyday work activities, haematologists produce descriptions of biological disorders, how they see and describe these disorders, how they narrate their cases to colleagues and persuade others about their diagnoses. It is within this broader study that Atkinson introduces the term 'practical phenomenology':

In these ways - as in many other areas of clinical medicine and pathology - the expert (primary physician, specialist, laboratory scientist) acts as a practical phenomenologist. He or she is concerned, as a matter of everyday work, with the nature of appearances and the production of descriptions. Those descriptions need to be adequate for the practical purposes of sharing and recording biomedical observations. They need to be sufficiently delicate to capture sometimes subtle variations in the appearance of tissues and traces. Equally, they draw on a register of occupationally given vocabularies that are a socially shared medium of description. (1995: 69-70, original emphasis).

Phenomenology is concerned with the 'undifferentiated unity of actual experience' (Ferguson 2001:232). Atkinson give this a sociological inflection: he emphasises that unity is socially achieved, focusing on how, in the practical course of affairs, people work up a world of shared objects. Specifically, he is concerned with the point that experts have to be trained in their expert ways of seeing. This is exactly what we would expect - haematologists need to be instructed in the particular ways of being a haematologist - however, expertise can occur at all kinds of levels, hence instructional activities can be found in even the most apparently simple areas:

I have, for instance, documented elsewhere some of the problems encountered by junior medical students in their attempts to produce descriptions of patients and their bodies that are regarded as adequate and accurate by their clinical teachers. The novice does not immediately see a pertinent desciption of, say, a 
patient's complexion. ... Observations are not selfevident to the 'unitiated'. In the absence of a conceptual framework and a descriptive vocabulary there is no socially shared 'observation': there is no agreement as to a stable world of phenomena. Hence, even agreement to describe a patient as 'pale' or 'jaundiced', or 'tanned' or the like is dependent on the situated vocabularies of clinical medicine. (1995:70)

It is often via what has been called 'instructed action' (see Garfinkel 1986), that practical phenomenology works. That is, from within situations we are practically instructed about the specific actions we need to learn to accomplish the practical activity at hand. This important point about the 'reflexivity' of knowledge and expertise is best understood by considering an extract from Atkinson's ethnographic data. Below is a strip of talk between an attending clinician $(A t)$, a clinical fellow $(F)$ and a student $(S t)$, conducted while they are looking down a multi-eyepiece microscope examining a blood smear (Atkinson 1995:78):

At: And there's a little cytosis, this cell here. Can hedge on that very nicely by saying Dr Lollard [the attending] got it smudged so I really can't commit myself.

St: $\quad$ Mhhm

At: And l'll have to accept that, but you could also try to guesstimate

St: I'm not sure if it er I'm not sure

At: Well we know it's not a lymphocyte

St: $\quad$ Right

At: We know it's not a neutrophil. We know it's not an eosinophil. We know it`s

St: $\quad=$ Like a mast?

At: $\quad=$ not a basophil

St: hehehm

F: $\quad$ Can't be a mast

At: It can't be a circulating mast. You don't get circulating mast cells

St: $\quad=$ Yeh huhm Ahm

At: $\quad=$ And that leaves us with one other denizen of the peripheral blood

St: $\quad$ Peripheral blood Umm

At: Like a monocyte, right?

Si: $\quad=$ Monocyte

\section{At: Okay? \\ St: Okay}

by $=$ )

(Emphasis in original; latching speech signified

The extract clearly shows the 'oral transmission of the craft skill of recognition' (Atkinson 1995:78), where 'craft' is not meant to downplay the technical complexity of haematology, but emphasises that it is socially transmitted knowledge. The student is being guided through the identification of various cell types, in situ, while all three peer down the microscope at the same blood smear. Key to note is that this learning of undoubtedly complex distinctions between cell types occurs through remarkably mundane procedures. These are the procedures of step-by-step interactional responsiveness: a cell is identified to look at; an acknowledgement is offered that all are looking at the same cell; some suggestions are offered by the attending clinician of what, specifically, is notable; the student indicates difficulty (note the 'ums' and 'ahs'); the clinician, through several turns at talk, dissolves that difficulty; and ultimately it is agreed they are looking at a 'monocyte', that is, the student has learned how to identify this particular haematological object. This instructed action, and note it is instructing about something that could well be 'life and death' knowledge, occurs through the pervasive mechanism of conversational turn-taking, perhaps the most fundamental bedrock of sociality (see Silverman 1998). Atkinson provides much more detail on this specific practical phenemenology, but we now have sufficient foundation to switch attention to some equally interesting 'transmission of the craft skill of recognition'. This time it is the workplace as a world of appearances that can be organised to produce descriptions of safety and hazards in the workplace.

\section{A Spectrum Documentary as Data}

On the ninth of February 2003 National Radio aired a documentary, 'Watch Out Here Comes OSH' (Spectrum, 2003). It adopts a simple technique: an interviewer (Gina Murphy) follows an OSH inspector (Rob Burse) ${ }^{1}$ about in the course of his everyday work, asks questions and tapes the answers, along with any interactions with employers/employees in the workplaces they visit. This tape has been transcribed to form my data; analysis of it is guided by a desire to pay close attention to detail, hence transcription includes 'ums' and 'ahs' and = symbols to indicate latching speech (the analysis presented below uses some basic principles of conversation analysis - see Silverman, 1998).

Below, frequent comparison with the practical phenomenology of the haematologists will be made. Regarding this, there is an initial point to emphasise: the haematologists' training is significantly different from what we hear in the Spectrum documentary, the difference being that the haematology students are frequently looking at tissue smears that are known to contain 'abnormal' or notable cell types. That is, their 
trained instructors (the attending clinician, the fellow, and their technicians) have selected the particular smears for what they contain and can teach about known diseases of the blood. In contrast, and this becomes important in the analysis below, in the workplaces the $\mathrm{OSH}$ inspector and the documentary maker visit, accidents, injuries, diseases and so on have not yet happened (or may in fact never happen). Of course, OSH work does involve post-event investigation of accidents, fatalities, and injuries, but in this documentary this is not the case. Rob and Gina are operating in the realm of risks and hazards, attempting to convey the preventative aspects of OSH work. Hence, the practical phenomenology they engage in may well be more complex than that seen with the haematologists. The latter, through scientific techniques of standardisation and miniaturisation (the microscope), are able to isolate what is under examination, whereas in the former, such isolation is almost impossible - the workplace remains a heterogenous, complex, social world that resists easy standardisation.

The tape begins with the sound of street traffic and an unidentified voice speaking: "within probably two blocks of where we are standing now there are probably two very suspect builders who are very reactive. They'll only do anything if we go down and stop them .... The voice continues for a little, then the introduction proper begins: 'It's this sort of attitude that's keeping the accident and fatality rates in the New Zealand construction industry among the highest in the western world. I am Gina Murphy and I'm going to spend the day with occupational safety and health inspector, Rob Burse'. Right from the beginning then, the documentary emphasises 'negatives': it is titled 'Watch Out Here Comes OSH', and the first words emphasise employer resistance and reactivity. Interestingly, given my point about difference above, this can be seen as similar to Atkinson's haematologists, that is, from the start Rob and Gina have narrowed down their ambit from the impossibly large topic of 'health', to a framing of $\mathrm{OSH}$ as concerned with surveillance and 'problems'. So, just as the clinican, fellow and student are united in a tacit understanding that they will be looking at smears containing disease, Rob and Gina do begin with a very generalised 'problem setting': in the documentary they will be focusing on problematic, negative entities in the workplace. This could be seen as the very first move of any practical phenomenology: a frame is provided to focus inquiry from unmanageable levels, to more tractable areas of interest.

This is reinforced in the very next move. Again we hear the noise of the street - it seems Rob and Gina are on the move - and then we hear Rob: 'Fifty percent of all fatalities are attributed to a fall. In fact the last fatality in Wellington two months ago was a fall'. Just as in Atkinson's extract where the attending clinician, fellow, and student begin from broad identifications, then gradually move down in level of refinement, this can be seen as an equivalent setting of a broad, easily accepted, identification. Half of all fatalities are attributed to falls we can agree on that as an easily acceptable hazard - but then, just like the haematologists, we need to refine our identification. Rob then details some specifics of the fall hazard; he gives an example from the 'week before' where he had to caution about the risk of falls "two little chaps ... both Polish, one of them couldn't speak English and the other one was very deaf'. Hence, he is refining his identification of risky objects: we all know that height is a risk factor, particularly in the construction industry, but when we look closer it is not sufficient to tell workers to be careful, because the trouble is sometimes they do not speak or hear English. This may seem a trivial point, however, it is important for we can already see a significant structure developing in this data. It is very similar to the practical phenomenology of the haematologists, that is, begin with a general framing move, then introduce something 'known and accepted', then work down in levels of specificity.

The first example in this data of real engaged practical phenomenology occurs after this general scene-setting work is accomplished (about 2 minutes running time). There is also a third party involved here ( $\mathrm{J}$ for Jonathan):

R: Okay I'll just introduce you to Jonathan. Jonathan's the, ah, the project builder

J: Yes, sort of, yeh
G: Tell me a bit about what you're doing here
Jonathan

J: We're just building some new apartments, rooftop apartments

R: This is one of the situations I was telling you about before, how, ah, things in the construction industry can change day by day, you know, like this morning at seven o'clock it actually wasn't too bad. And where we are here it's like a wind funnel coming up Taranaki Street and that can change the whole, ah, safety, ah, we're just talking about safety today, the whole safety dynamics of the site

J: Yeh, ah yeh, I've just had to cancel the crane for the day you know

This excerpt starts with the introduction of Jonathan and his role, and a question from Gina about what he is working on. These are clearly geared up for the 'overhearing audience', that is, normally a builder on site would not have to explain what they were working on. In other words, we are seeing here a certain artificiality to the interactive talk. Nevertheless, we see in the larger stream of talk from Rob a useful insight into the particular nature of OSH practical phenomenology. What Rob does is to take the simple identification of a physical worksite - the rooftop apartments - and emphasise a key interest in a temporal dimension. In the fifth line, his first move indicates he wants to take an extended turn at talk: 'This is one of the situations I was telling you about before'. That is, he says, note this, this is important: let's move from the apartments as an obvious object and apply some previous knowledge. So, previous knowledge now structures seeing, and in doing this Rob is acting exactly in the same pedagogical role as the attending clinician. In effect, he asserts his expertise, his knowledge about how to look at things like work on rooftop apartments. He then introduces his key insight: "how things in the 
construction industry can change day by day'. Again this may seem trivial, but it is in fact remarkably important, for what Rob does here is show that seeing is not enough. Seeing a rooftop apartment (ie. height) and knowing that falls are a major source of fatalities, is readily available; he adds the extra point that conditions change, that is, to height has to be added the possibility of change in conditions over time. In itself this knowledge is not spectacular - it is perfectly sensible, and indeed Jonathan cancels the crane - but it does show, mirroring the haematologists, that seeing in itself is never enough. In emphasising this, Rob constructs his OSH inspector role as involving specialised knowledge, or to use Atkinson's apposite phrase, 'the craft skill of recognition'.

\section{The problem of commonsense and the extendable}

As we work through the documentary two linked problems arise. Firstly, it is apparent that as he proceeds through various workplaces much of what the $\mathrm{OSH}$ inspector points to as a danger and hazard is thoroughly well known and seems like plain commonsense. This does not stop them from being a danger or hazard - they may indeed claim someone's life - but it does make the interactive work of pointing out such danger, and then getting it acted upon, all the more difficult. Below is a data excerpt that runs on directly from that above where Rob informs Jonathan that OSH is targetting 'noise' hazards:

R: $\quad$... So what we've done, we've just lately we've gone round and taken photographs of a number of tools that you would typically find on a construction site ranging from a little palm sander to a ramset gun and we ve checked the, when they're in operation the sound that they make, okay. The big ones that you've got to worry about are up here, the ramset gun, based on that 85 decibel exposure per day you only have to fire one charge without any hearing protection and you've used up your safe $=$

J: $\quad=$ Oh, all right, huh, I've just noticed one of my subcontractors they're grinding some concrete and ah .. Huhhuh without anything

R: Right

J: So you know, so=

G: =Do you say anything to them?

J: I did. Yeh, I did discuss it with him, um. I mean his employer should obviously be issuing them with, you know, probably a dust mask as well, um

\section{G: What did he say}

J: $\quad$ So I raised that with him. Not a whole lot, I think he was going to go off and chase his boss to, to sort something out for him

The striking thing in this extract is how strained it seems. Rob shows the photographs of high-noise tools, and before he can finish Jonathan interjects with a noticing of workers grinding some concrete without protective ear equipment. This is relevant to Rob's topic, but what we see next is a minimal response from Rob - 'Right' - then Jonathan tries to pick up the topic but is interrupted by Gina asking if Jonathan said anything to the workers. In reply, he indicates he did, but then almost changes topic by introducing the question of dust mask protection. Overall, it is a relatively disconnected strip of talk: the topic under discussion set up by Rob is quickly neglected, other topics are introduced and not followed up, and in fact the person who introduced the topic, hence having the right to regain a turn at talk, loses that potential for five turns of talk (after this extract Rob does goes into an extended turn at talk, perhaps an attempt to steer the talk back on topic).

It can be argued that the talk is this way because the speakers are dealing with things that appear commonsense, that is, they are straining to find suitable 'content' about which to develop sustained talk-on-topic. This is similar to a finding from other research into the transmission of safety knowledge. Lloyd and Roen (2002) studied what firemen do when they offer fire safety assessments in residents' households. They found that

In the course of their fire-safety assessments, some firefighters tailored their comments to the audience but did not necessarily confine their advice to fire-safety issues. Across a number of safety assessments, firefighters gave residents tips on interior decorating and saving power, made suggestions about general child safety, and talked about the risk of electrocution. (2002: 148)

Lloyd and Roen call this the 'problem of extendability'. Again this arises from a situation where because risk factors are fairly well known, or at least can be easily itemised, and this knowledge is being assessed in a live interactive situation, interactants struggle to find things to say. Consequently, they extend talk to things which, strictly speaking, are not directly relevant, functioning much like phatic communication.

In the current data, there is an interesting development of this problem of extendability. That is, Rob literally cannot escape looking about him and seeing, and commenting on, potentially risky objects and practices. Consider the following extract:

G: What's the silliest thing that you've ever seen, you know, seen being on site

R: One of the most stupid things I ever saw was [Rob provides a lengthy story] ... But this is, I do carry round examples with me, these photos were taken by me when I was walking up Lambton Quay. This is how you can never get away from it . huh This was a chap with a stepladder adjacent to a, ah, stop and go sign and it's a 9 step ladder, okay. An aluminium ladder. And you can see here that he's got it balanced on bricks on one style of the ladder. Now that instantly alerted me to something, because that's unstable as you can see. So, I took a photo 
of it, and then I walked slightly past and I looked at the ladder and I could see the stabilising bars weren't clipped into the locking stays on both sides. So not only is it possible that the ladder is gunna move laterally, it could ... collapse apart. And look at that photo there. He's standing on the top rung. Now that guy there was the foreman .. so he, there was another issue. I was a bit worried about getting him down because I thought he'd panic because people do panic sometimes when they see OSH, hh, so I whistled and I got him down off the ladder and asked him to explain his actions. Now he would have fallen .. 2.1 metres. Now is that a significant fall, I don't know. Because the thing is if he landed he could hit himself on the concrete down here. Now that was a very stupid act. A very stupid act.

In response to Gina's probe to tell about the 'silliest thing that you've ever seen', Rob tells two stories. The first, omitted above, details a worker unhooking himself from a safety harness and climbing out of a 'swinging stage' ten floors up a building. The 'ladder story' follows the detail of this obviously dangerous action, and this is partly why it is interesting. Rob actually goes into more detail on the latter, including showing photographs, and while a fall from a ladder could indeed be injurious, it does seem more ambivalent than the first story. Firstly, in his practical phenomenology Rob builds up a list of noticings: the build and balance of the ladder; the 'foreman' on the top rung; below is concrete. Then, a significant part occurs where Rob says, Now he would have fallen .. 2.1 metres. Now is that a significant fall, I don't know'. Note that he does not say 'about two metres', or 'six foot', he is very specific in his measurement: he pauses, perhaps indicating thinking, then states '2.1 metres'. Rob chooses to use what Sacks (1992: 183) calls 'precise' rather than 'approximate' numbers, when in fact it is usual in describing height in such a situation to use the approximate measure. It can be argued that what this precise measure does is emphasise Rob's expertise - he is speaking here as an expert - and the interesting consequence of this is to reverse the effect of him saying that he does not know whether that was a significant height. It is clear that he does think it was a dangerous height, and he partly indicates this by using the precise number. Thus we see Rob caught in an attitude of extendability, as he himself says, 'you can never get away from it', and we see that even a ladder height of ' 2.1 metres' is worth photographing as a record of everyday risks.

It should be clear, however, that extendability has to be tempered. A ladder height of 1.1 metres, in certain circumstances, could also be dangerous, but to photograph such a circumstance and call it a 'very stupid act' is taking things too far beyond what everyone can readily agree is dangerous. Hence, the OSH Inspector's practical phenomenology is in no way a 'private language': the whole point of the enterprise is to get others in the workplace to see appearances, and make descriptions of them (hence hoping to change actions), in the same manner. This is through and through a social activity, and one that involves careful balancings of the 'obviously' risky, and those that need more careful craft skill applied in order to unearth their dangerous nature.

\section{Conclusion}

Frequent comparisons have been made above between the practical phenomenology of haematologists and the $\mathrm{OSH}$ inspector. To reiterate, these two practical activities involve very different bodies of substantive knowledge, however, it should be clear that as a formal procedure, that is, a technique for accomplishing a shared social world, practical phenomenology cuts across these different spheres.

A key thing to note from this study is the extreme difficulty of the work of OSH inspection. Here, the comparison with haematology is very useful. Obviously, we do not all know how to distinguish and label the celltypes we hear about in the transcript from Atkinson's data - these words are from a foreign language. But we all know, as competent everyday persons, that falling from a height is dangerous; we all know that noisy tools can damage our hearing; we all know that when a high wind comes up we might have to change our building plans for the day. For sure, there are potential intricacies to such knowledge, nevertheless, given a core of commonsense to it, the OSH Inspector is caught in a bind. He has expert knowledge, even to the extent that everywhere he looks he can see an accident waiting to happen (the extendability problem), but when it comes to the realm of facing employers and employees in the workplace, that is communicating this knowledge, there is only so much he can say. At heart, if you try to explicate commonsense too often or too far, you end up losing face, having doubts expressed about your competence, usefulness, and so on. It is not hard to see many workers nodding acquiescence to the OSH inspector's suggestions, but then, once he has gone, returning to their potentially dangerous workplace practices. Much research into $\mathrm{OSH}$ realises this, but here I have shown, through some empirical data, what it looks like in the dynamic stream of real life interaction, that is, the realm of practical phenomenology.

Those interested in further research on occupational health and safety might draw one major point from this article. To do so, first requires avoiding assumptions about what is trivial or important data. Many would gloss over a radio documentary as inconsequential, however, within the limited space available, I have shown that this is detailed, useful, data. If this step can be made, the question to ask is: how much of the freight of academic analysis of $\mathrm{OSH}$ matters is carried by the practical phenomenology, the commonsense processes, which are tacitly and unsystematically deployed and depended upon in that work of academic analysis? In other words, we are all dependent on taken for granted abilities to select out and see certain things, and not others, as dangerous and risky. To ask how this is done, as social and practical action, through examining good empirical data, begs further inquiry.

\section{Notes}

1. Hereafter the two main speakers in the documentary will be referred to as 'Rob' and 'Gina', respectively $R$ and $G$ in the transcript excerpts. 


\section{References}

Atkinson, P. (1995). Medical Talk and Medical Work. London: Sage.

Duncan, G. (2003). Workers' compensation and the governance of pain. Economy and Society, 32(3), 449-477.

Ferguson, H. (2001). Phenomenology and social theory. In Ritzer, G. and Smart, B. Handbook of Social Theory. London: Sage.

Garfinkel, H. (1986) Ethnomethodological Studies of Work. London: Routledge and Kegan Paul.

Lamm, F. (2000). Occupational health and safety in New Zealand. In Bohle, P. and Quinlan, M. Managing Occupational Health and Safety: A Multidisciplinary Approach. Sydney: Macmillan.
Lloyd, M. (2002). Occupational Health and Safety in New Zealand. Palmerston North: Dunmore.

Lloyd, M. and Roen, K. (2002). 'When you smell smoke ..': 'Risk factors' and fire safety in action. Health, Risk \& Society, 4(2), 139-153.

Sacks, H. (1992). Lectures on Conversation. Vol II. Cambridge: Blackwell.

Silverman, D. (1998). Harvey Sacks: Social Science and Conversation Analysis. New York: Oxford University Press.

Slappendel, C. (1995). Health and Safety in New Zealand Workplaces. Palmerston North: Dunmore.

Spectrum (2003). Spectrum - Watch Out Here Comes OSH. (Replay Radio recording). Wellington: Radio New Zealand. 